Louisiana State University

LSU Digital Commons

7-31-2014

\title{
Anion-induced dimerization of 5-fold symmetric cyanostars in 3D crystalline solids and 2D self-assembled crystals
}

\author{
Brandon E. Hirsch \\ Indiana University Bloomington \\ Semin Lee \\ Indiana University Bloomington \\ Bo Qiao \\ Indiana University Bloomington \\ Chun Hsing Chen \\ Indiana University Bloomington \\ Kevin P. McDonald \\ Indiana University Bloomington
}

See next page for additional authors

Follow this and additional works at: https://digitalcommons.Isu.edu/chemistry_pubs

\section{Recommended Citation}

Hirsch, B., Lee, S., Qiao, B., Chen, C., McDonald, K., Tait, S., \& Flood, A. (2014). Anion-induced dimerization of 5-fold symmetric cyanostars in 3D crystalline solids and 2D self-assembled crystals. Chemical Communications, 50 (69), 9827-9830. https://doi.org/10.1039/c4cc03725a

This Article is brought to you for free and open access by the Department of Chemistry at LSU Digital Commons. It has been accepted for inclusion in Faculty Publications by an authorized administrator of LSU Digital Commons. For more information, please contact ir@lsu.edu. 
Authors

Brandon E. Hirsch, Semin Lee, Bo Qiao, Chun Hsing Chen, Kevin P. McDonald, Steven L. Tait, and Amar H. Flood 


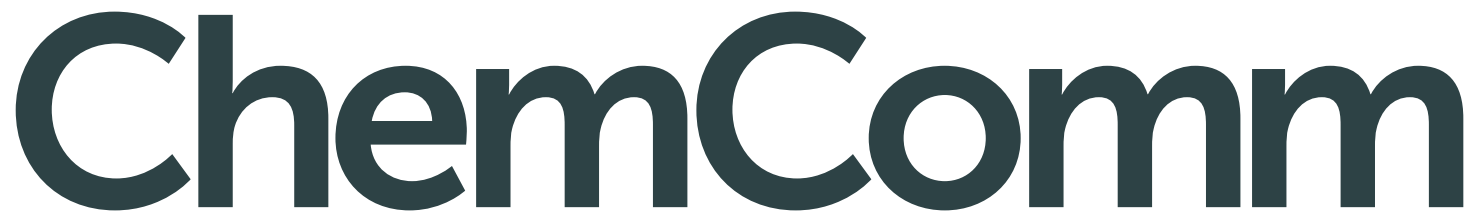

Chemical Communications www.rsc.org/chemcomm
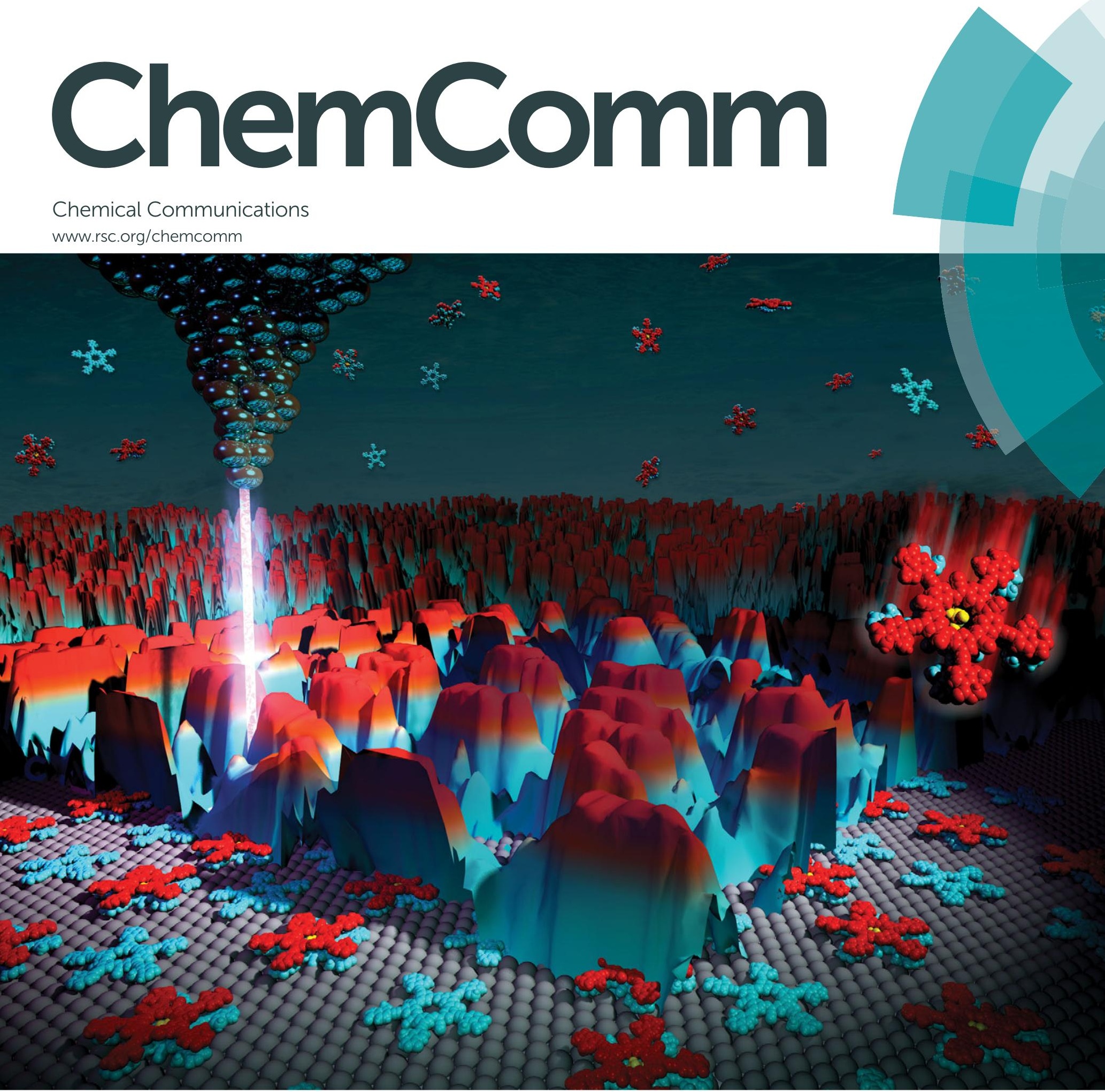

ISSN 1359-7345

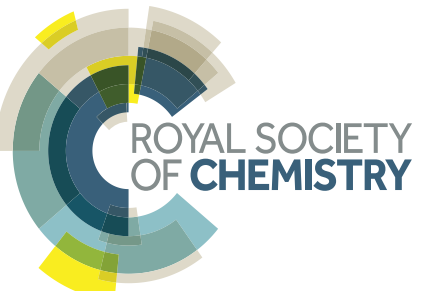

\section{COMMUNICATION}

Steven L. Tait, Amar H. Flood et al.

Anion-induced dimerization of 5-fold symmetric cyanostars in

3D crystalline solids and 2D self-assembled crystals 
Cite this: Chem. Commun., 2014, 50, 9827

Received 15th May 2014,

Accepted 26th June 2014

DOI: $10.1039 / \mathrm{c} 4 \mathrm{cc} 03725 a$

www.rsc.org/chemcomm

\section{Anion-induced dimerization of 5-fold symmetric cyanostars in 3D crystalline solids and 2D self-assembled crystals $\dagger$}

\author{
Brandon E. Hirsch, Semin Lee, Bo Qiao, Chun-Hsing Chen, Kevin P. McDonald, \\ Steven L. Tait* and Amar H. Flood*
}

Anions stabilize stacking of $C_{5}$-symmetric macrocycles, called cyanostars, into dimers in solution and herein we demonstrate this stacking in solid-state crystals. We further show that this guest binding can be applied as a route to bilayer growth at the solutiongraphite interface.

The bottom-up self-assembly of materials requires knowledge of how to encode contacts into molecular building blocks to program their packing. Such investigations can benefit from imaging at sub-molecular resolution using scanning tunneling microscopy (STM) of two-dimensional (2D) crystalline monolayers that exist in equilibrium with solution species at liquid-solid interfaces. ${ }^{1}$ Yet, other than discoveries of multi-layered assemblies, ${ }^{2-9}$ programmed growth away from the surface is rare. Thus, we seek here to investigate if known solution-phase intermolecular coupling can be exploited for 3D growth. We test this approach with cyanostars (Fig. 1), ${ }^{10}$ which are shape-persistent macrocycles that provide access to very stable $2: 1$ complexes with anions $\beta_{2} \sim$ $10^{12} \mathrm{M}^{-2}\left(\Delta G \sim 70 \mathrm{~kJ} \mathrm{~mol}^{-1}\right)$ constituted by dimers. Cyanostars also bear 5-fold symmetry, which presents intriguing opportunities to investigate ${ }^{11-14}$ possible $2 \mathrm{D}$ quasicrystal formation, though this outcome has been realized only once. ${ }^{15}$

In this Communication we show STM and X-ray crystallographic data verifying anion-promoted formation of $2: 1$ dimers of cyanostars. Cyanostars ${ }^{10}$ are an interesting new class of compounds that are synthesized in one pot with high yields by the cyclization of cyanostilbene repeat units. Cyanostars have a shallow bowl shape that we believe racemizes between the $M$ and $P$ stereoisomers in solution. ${ }^{10}$ These fascinating systems are of interest for solution-phase chemistry, solid state packing and surface functionalization. We therefore add appropriate substituents to study the cyanostars in each environment.

Department of Chemistry, Indiana University, 800 E. Kirkwood Ave., Bloomington, IN 47405, USA. E-mail: tait@indiana.edu, aflood@indiana.edu

$\dagger$ Electronic supplementary information (ESI) available: Syntheses, characterizations, NMR titrations, STM experiments and analyses, X-ray crystal structure analysis. CCDC 1003282. For ESI and crystallographic data in CIF or other electronic format see DOI: 10.1039/c4cc03725a (a)
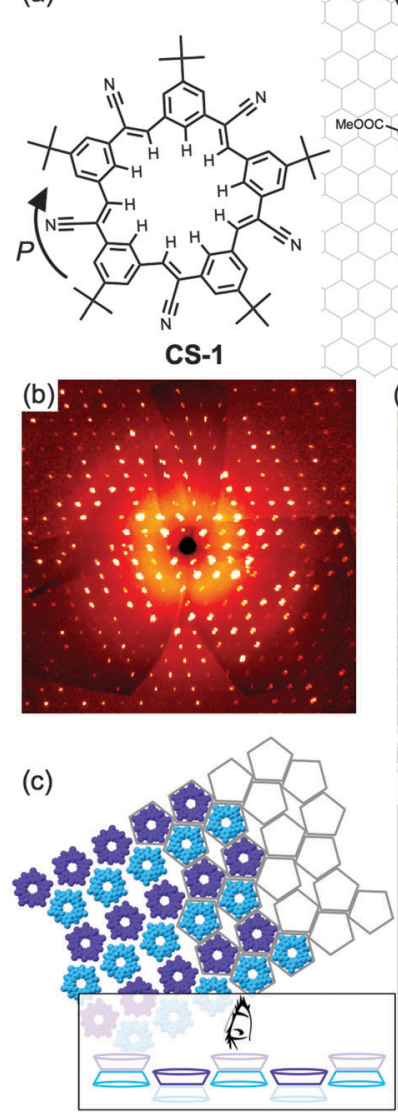

(d)
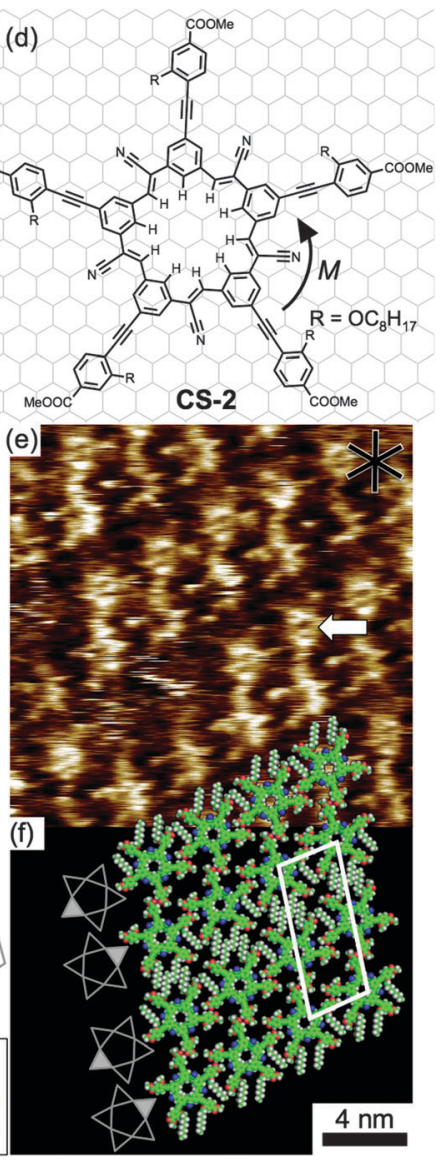

Fig. 1 Cyanostars (a) CS-1 and (d) CS-2 ( $P$ and $M$ stereoisomers). (b) Single crystal diffractogram (precession image) of CS-1. (c) 2D slice of molecular packing (Dürer tiling) from CS-1. (e) STM topography of CS-2 at the TCB/ HOPG interface. (f) Packing model of the 2D monolayer of CS-2 assembled into anti-parallel rows of star lamella. ([CS-2] $=5.1 \times 10^{-6} \mathrm{M}$, $I_{\mathrm{T}}=10 \mathrm{pA}, V_{\text {sample }}=-0.58 \mathrm{~V}$, unit cell $a=2.91 \pm 0.10 \mathrm{~nm}, b=5.82 \pm$ $0.28 \mathrm{~nm}, \gamma=99 \pm 4^{\circ}$ )

tert-Butyl substituents of CS-1 provide steric gearing for 3D crystallization. Cyanostar CS-2 incorporates ester-terminated 
phenylene-acetylene arms bearing octyl $\left(\mathrm{C}_{8}\right)$ chains, which serve as solubilizing agents during the synthesis and help to stabilize the molecules at the surface of highly oriented pyrolytic graphite (HOPG). X-ray crystallography shows two tert-butyl-substituted cyanostars (CS-1) coordinated around a perchlorate $\left(\mathrm{ClO}_{4}{ }^{-}\right)$ anion. Similarly, the 2D crystallization of CS-2 shows dimer formation upon addition of hexafluorophosphate $\left(\mathrm{PF}_{6}{ }^{-}\right)$anions. Both anions bind with high affinity to cyanostars. ${ }^{10}$

Solution and refinement of the X-ray diffraction ${ }^{10}$ (Fig. 1b) obtained for crystals of cyanostar CS-1 showed how one slice of the crystal produced a 2D Dürer tiling ${ }^{16}$ (Fig. 1c). Dürer's pentagons show close contacts between three edges leaving a rhombic void. Single slices of CS-1 share this packing albeit with lowered symmetry related by an $5^{\circ}$ in-plane rotation. Related cyclic aryl-amide pentamers display different packing within single crystals. ${ }^{17}$ While this packing exists within the solid state, it results from a slice through offset dimers (see inset to Fig. 1c). Thus, it is not directly apparent if this would be reproduced on a flat surface.

2D-crystallization of CS-2 onto a graphite plane was investigated at the interface formed between solutions of CS-2 in 1,2,4trichlorobenzene (TCB) and freshly cleaved HOPG. For synthetic feasibility, the $\mathrm{C}_{8}$ chain was located ortho to the acetylene linkage. When a droplet $(\sim 15 \mu \mathrm{L})$ of CS-2 $(5 \mu \mathrm{M})$ was deposited onto the surface, localized domains $\left(40 \times 40 \mathrm{~nm}^{2}\right)$ of order can be observed (ESI, $\dagger$ Fig. S1). High-resolution scans $\left(20 \times 20 \mathrm{~nm}^{2}\right.$, Fig. 1e and ESI, $\dagger$ Fig. S2, S3 and S5) reveal the five points of the cyanostars (Fig. 2). Interestingly, CS-2 on HOPG does not exhibit the same Dürer tiling present in the CS-1 crystals. Rather, the CS-2 packs at the surface in pairs of anti-parallel rows with the stars in each row aligned with an apex pointing along the row direction (apex of one star nested into the crevice of the next, Fig. 1f). The two-molecule unit cell parameters were measured to be $a=2.91 \pm 0.10 \mathrm{~nm}, b=5.82 \pm 0.28 \mathrm{~nm}$, and $\gamma=99 \pm 4^{\circ}$ (ESI, $\dagger$ Fig. S2) after image correction by measuring graphite with atomic resolution (ESI, $\dagger$ Fig. S4). In some cases, the central cavity of the macrocycle can be resolved (Fig. 2). A dark stripe is observed between the anti-parallel double rows of CS-2 lamella. This region is attributed to $\mathrm{C}_{8}$-chains that are adsorbed and likely aligned along an axis of graphite (ESI, $\dagger$ Fig. S5).

The tentative packing model was constructed using a selfconsistent strategy that is reminiscent of the molecular
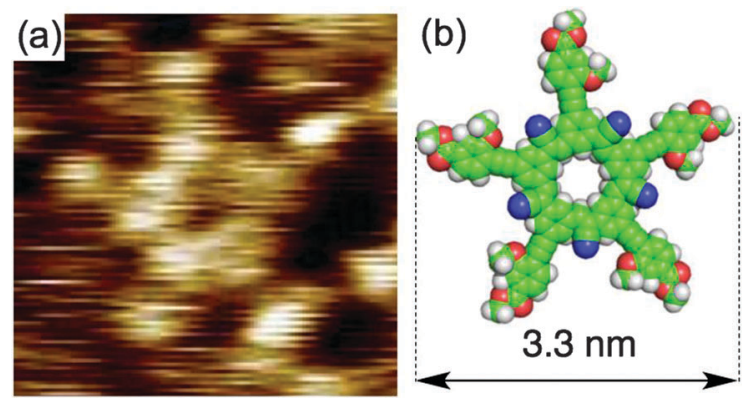

Fig. 2 (a) STM image at TCB-HOPG interface $\left(T=23 \pm 0.2^{\circ} \mathrm{C}, I_{\mathrm{T}}=10 \mathrm{pA}\right.$, $V_{\text {sub }}=-0.58 \mathrm{~V}$ ) and (b) molecular model of CS-2. replacement methods ${ }^{18}$ typically used with the structure refinement of low-resolution X-ray crystal data obtained from single crystals of biomolecules. In contrast to electron density maps from X-ray crystallography, however, an STM image is a realspace contrast map of the scanning tip's $z$-position as it maintains a constant tunnelling current, i.e., a convolution of surface topography with local electronic density of states near the Fermi level. The error signal image (deviation of actual tunneling current from constant set-point) is also useful in resolving $2 \mathrm{D}$ surface structures. The workflow for deriving $2 \mathrm{D}$ supramolecular packing and local structural information from these images is described in the ESI (See page S6). $\dagger$

The packing model for $\mathbf{C S}-\mathbf{2}_{(\mathrm{TCB} / \mathrm{HOPG})}$ suggests that the esters at the star's tips form two attractive contacts (ESI, $\dagger$ Fig. S6). The first helps form a seamless interface between the paired rows of stars. The second allows contact between stars along each row (Fig. 1f). Similar contacts have been observed in the ordering of ester-terminated pentamers. ${ }^{14}$ The model shows sufficient space for adsorption of three alkyl chains per CS-2, although the chains were never fully resolved (ESI, $\dagger$ Fig. S5). Two alkyls are believed to be interdigitated with two from the adjacent row and one alkyl sits between stars along the row. The remaining two chains could be undergoing on-off dynamics by either filling space near the surface (on) or back-folded into solution (off), as is commonly observed. These two chains are represented by methyls in our model (Fig. 1f). Cyclic pentamers of alkyl-substituted phenylene ethynylenes showed similar lamella ${ }^{14}$ at liquid-solid interfaces while corannulenes studied under ultra-high vacuum displayed a variety of packing. ${ }^{19,20}$

Our model of the 2D crystal structure of CS-2 differs from the solid state structure of the parent cyanostar CS-1, ${ }^{10} c f$. Fig. $1 \mathrm{c}$ and $\mathrm{f}$. Cyanostars have shallow bowl-like shapes (ESI, $\dagger$ Fig. S14) that produce two faces and, just like $C_{5}$-corannulenes ${ }^{21,22}$ (buckybowls), they are chiral and racemize rapidly between enantiomers. Analysis of crystal data for CS-1 revealed ${ }^{10}$ whole molecule disorder (WMD) where either an $M$ or $P$ enantiomer is located on the lattice site, i.e., enantiomers pack in a similar manner. Considering the STM data, limits of resolution and the small differences between enantiomers, an assignment of the chirality to individual molecules within the $2 \mathrm{D}$ crystal could not be made. That is, even though the tips of the stars can be seen in some of the images (Fig. 2), we do not resolve significant topographical differences between two stereoisomers. This finding is consistent with our molecular modelling that isomorphic replacement of $M$ for $P$ enantiomers leads to co-localization of the arms (primary differences exist in the direction of the $\mathrm{CN}$ groups). ${ }^{10}$ Chirality emerging at the supramolecular domain level is not observed because lamella rows lie along graphite's major axes for both possible conglomerates (ESI, $\dagger$ Fig. S4), e.g., one difference would be the angle of the alkyl chains between double rows and these are not clearly resolved.

The degree of curvature present in the bowl-like CS-2 is an outstanding question. The measured length of the stars in the STM image $(\sim 3 \mathrm{~nm})$ and the $2 \mathrm{D}$ unit cell packing distances indicate minimal buckling. It is reasonable that vdW interactions with the surface may act to enhance the molecule's planarity. 

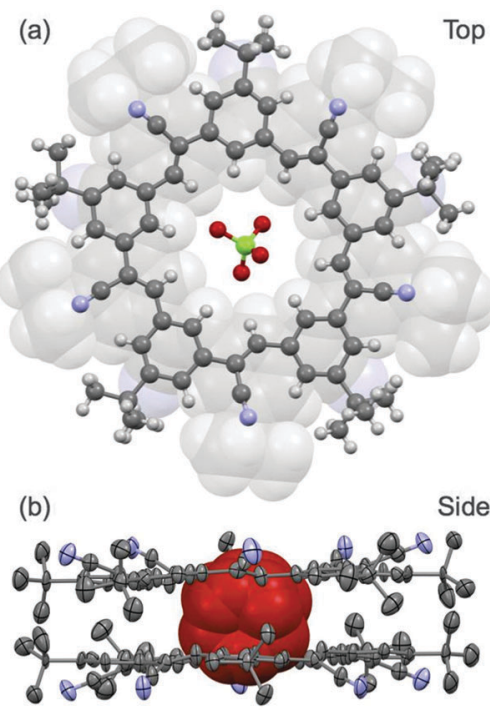

Fig. 3 X-ray crystal structure of $\mathrm{CS}-\mathbf{1}_{2} \cdot \mathrm{ClO}_{4}^{-}$: (a) view from top shows one possible $P / M$ pair and one of the disordered anions. (b) Side view with hydrogen atoms omitted for clarity and ellipsoids drawn with $50 \%$ probability. All rotational orientations of $\mathrm{ClO}_{4}{ }^{-}$are represented as a spacefill model. Disordered $\mathrm{TEA}^{+}$cations were eliminated during the refinement using Platon SQUEEZE.

Next we investigated the opportunity to extend the monolayer order into the 3rd dimension, i.e., away from the surface using anions to form crystalline dimers. In organic solutions ${ }^{10}(40: 60$, methanol: dichloromethane), cyanostar CS-1 forms dimers by making sandwich complexes around large anions $\left(\mathrm{X}^{-}\right)$:

$$
\mathrm{CCS}-1+\mathrm{X}^{-} \rightleftharpoons \mathrm{CS}-\mathbf{1}_{2} \cdot \mathrm{X}^{-} \quad \beta_{2}
$$

While sandwich complexes have been observed in the solid state structure of a [3]rotaxane, ${ }^{10}$ we report the first crystallographic evidence of a sandwich formed around $\mathrm{ClO}_{4}{ }^{-}$and consider the emergence of such structures at solution-surface interfaces.

X-ray crystallography shows the solid-state structure of the $\mathbf{C S}-\mathbf{1}_{2} \cdot \mathrm{ClO}_{4}{ }^{-}$. tetraethylammonium (TEA ${ }^{+}$) complex (Fig. 3). $\mathrm{A} \mathrm{ClO}_{4}{ }^{-}$anion is sandwiched between two CS-1 molecules and bound jointly to their cavities. Of the 20 internal hydrogen atoms, 15 form short-contact hydrogen bonds $(d \leq 3 \AA)$ with $\mathrm{ClO}_{4}{ }^{-}$(ESI, $\dagger$ Fig. S16). The WMD of CS-1 and its bowl curvature can be seen after refinement (ESI, $\dagger$ Fig. S14). The stacked dimer is rotationally staggered, in part from the steric gearing of the tert-butyl groups. The extended Dürer tiling of CS-1 is maintained in the $\mathrm{ClO}_{4}{ }^{-}$bound structure with slight deviations away from the tiling plane (ESI, $\dagger$ Fig. S15).

The $\mathrm{ClO}_{4}^{-}$anion is disordered (Fig. 3b). Four different rotational orientations of the anion were used during refinement, where two of each orientation is symmetrically related to the other two, and the occupation percentages refined at $\sim 60: 40$. A view (Fig. 3b) showing both occupancies of the $\mathrm{ClO}_{4}{ }^{-}$anion indicates the anion could be easily represented by a sphere.

Investigations into the ability of the molecules to maintain this dimer binding configuration when condensed on the surface were conducted with the aid of $\mathrm{PF}_{6}{ }^{-}$, which forms the strongest 2:1 sandwiches in the solution phase. ${ }^{10}$ Ex situ mixing experiments used a CS-2 solution $(500 \mu \mathrm{M})$ and a solution of $\mathrm{PF}_{6}^{-}(2.5 \mu \mathrm{M})$ as the $n$-tetrabutylammonium $\left(\mathrm{TBA}^{+}\right)$salt. Under these conditions and given the large stability of the complex, ${ }^{10} 1 \%$ of the cyanostars in solution are likely converted into sandwich complexes (eqn (1)). This solution $(10 \mu \mathrm{L})$ is then deposited onto HOPG. Current leakage present during STM experiments prevented imaging. After equilibration for 20-40 minutes, the HOPG was gently rinsed with two streams of neat TCB $(\sim 20 \mu \mathrm{L})$. Approximately $5 \mu \mathrm{L}$ of TCB is believed to remain on the surface during scanning. Presumably, washing removes the majority of molecules present in the soaking solution while leaving the adsorbed molecules behind.
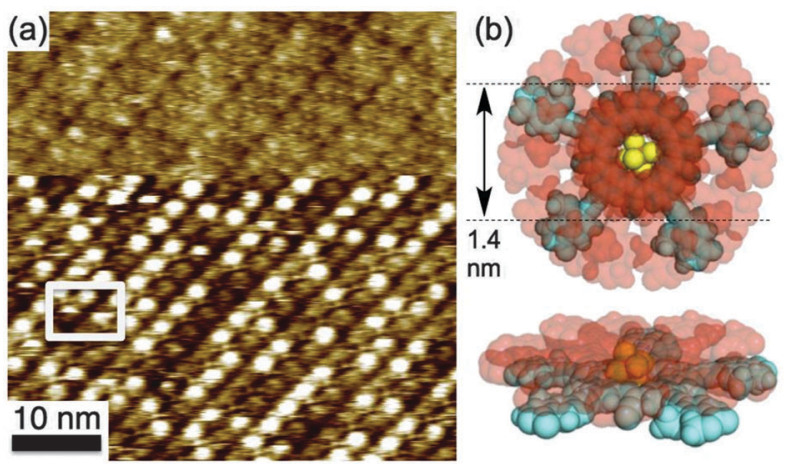

Fig. 4 (a) STM image showing the bright features assigned to dimers $\left(\mathrm{CS}-\mathbf{2}_{2} \cdot \mathrm{PF}_{6}{ }^{-}\right)$that were first resolved on the surface after a tip change (see text for details). The white box highlights a $\mathbf{C S}-\mathbf{2}_{2} \cdot \mathrm{PF}_{6}{ }^{-}$dimer that has come and gone at adjacent lattice sites in between scan lines. $\left(I_{\top}=0.10 \mathrm{nA}\right.$, $V_{\text {sample }}=-0.702 \mathrm{~V}$ ). (b) Model of CS-2 $2 \cdot \mathrm{PF}_{6}{ }^{-}$(yellow anion), lower CS-2 in cyan, and rotationally active upper CS-2 in red.

STM imaging at the resulting interface (Fig. 4a) showed retention of the double rows of the cyanostars CS-2 that were previously observed with CS-2 prior to anion addition (Fig. 1e). Initially, a serendipitous tip change brought bright circular features into view in the same image. This discovery was subsequently replicated in nine unique experiments. When the anion was absent, no height contrast was ever observed. We assign these bright features to the presence of sandwich complexes where dimers are formed around a single $\mathrm{PF}_{6}{ }^{-}$anion, CS- $\mathbf{2}_{2}$. $\mathrm{PF}_{6}{ }^{-}$. The alternative possibility involving co-adsorption of the $\mathrm{TBA}^{+}$countercation is unlikely. First, it is known $^{10}$ that such $1: 1: 1$ ion-pair complexes, $\mathbf{C S}-2 \cdot \mathrm{ClO}_{4}{ }^{-} \cdot \mathrm{TBA}^{+}$, are less stable than the sandwich complexes under these solution conditions examined. Second, the bright circular features have the same diameter of $\sim 1.4 \mathrm{~nm}$ as the cyanostar signatures in the first layer of the same image, which also matches the diameter of the cyanostar core (Fig. $4 \mathrm{~b}$ ) of $\sim 1.4 \mathrm{~nm}$ and is thus too large to correlate to the $\sim 0.8 \mathrm{~nm}$ size of the $\mathrm{TBA}^{+}$cation (ESI, $\dagger$ Fig. S8). In addition, no features were resolved that could be attributed to the $\mathrm{TBA}^{+}$counter cation. Similar to other studies, the counterion species is not observed, ${ }^{6-8}$ expect in a few cases. ${ }^{23,24}$ We believe the solvated cation contributes to a diffuse double layer. ${ }^{25}$

Height profiles of these bright features give an average stack at $1.4 \AA$ above the other receptors (ESI, $\dagger$ Fig. S7), which is 
comparable to the height measurement of the first monolayer (0.8-1.4 $)$. The second layer is dynamic. Occasionally, complexation or decomplexation events are captured (Fig. 4a, white box) when half-circles appear or disappear between scan lines. ${ }^{26}$

Unlike the star shapes of the monolayer of CS-2, submolecular resolution was not achieved for dimers; they always appear as circles with irregular edges. We believe that either partial rotations of the topmost cyanostar (Fig. 4b) or static stereochemical pairs (chiral or meso) produce this outcome.

Rotational preferences in the top-most surface-active CS-2 are less defined than the steric gearing in CS-1. The circular appearance in the second layer may result from the CS-2 rotating about the anion faster than the time scale of the STM imaging $\left(0.2 \mathrm{~ms}\right.$ per $0.1 \times 0.1 \mathrm{~nm}^{2}$ pixel $)$. The "blurred" molecule contrast would indicate $>1$ rotational movement of a CS-2 in less than $0.2 \mathrm{~ms}$. Given that most first-order processes are complete within three half lives, then the rotational barrier must be less than $12 \mathrm{kcal} \mathrm{mol}^{-1}$ at $296 \mathrm{~K}$.

The intermolecular contacts helping to determine the stability of the second cyanostar, CS-2, must differ from those that led to adsorption and ordering of the self-assembled monolayer onto the graphite. In the first layer, interdigitation of alkyls (Fig. 1f) will help lock the rotational orientation of each cyanostar. These contacts, both with the surface and neighboring chains, are expected to be less important in the second layer. Nevertheless, we expect the length of the CS-2 arms to provide some degree of gearing between neighbours - as seen in the packing model (Fig. 1f). We believe the primary contact that stabilizes the second cyanostar originates from anion binding, which amounts to $\sim 70 \mathrm{~kJ} \mathrm{~mol}^{-1}$ for the sandwich. Regarding the rotations with CS-2, we note from the crystal structure of CS-1 around $\mathrm{ClO}_{4}^{-}$(Fig. 3b) that the anion is disordered. This feature is indicative of a shallow rotational potential that could allow easier rotations. Rotational dynamics of receptors are rare; however dynamic anions have been observed. Rotations of $\mathrm{CN}^{-}$occur in crystals ${ }^{27}$ and in triazolophane macrocycles. $^{28,29}$

Attempts to enhance surface dimerization with more anion led to unstable assembles. Imaging of CS-2 in octanoic acid produced short-range order (ESI, $\dagger$ Fig. S11) where the shape and cavity can still be resolved. Annealing (up to $30{ }^{\circ} \mathrm{C}$ ) had no effect.

We have shown formation of anion-binding dimers constituted by cyanostars in 3D solids and in self-assembled 2D crystals at the solution-solid interface. This work shows the first observation of anion dimer complexation on a surface. We show how solution phase functionalities can be rationally modified and designed for developing surface-active supramolecular self-assemblies.

ChemMatCARS Sector 15 is principally supported by the NSF/DOE (CHE-1346572). Use of the APS was supported by the US DOE, Office of Science, Basic Energy Sciences (DE-AC0206CH11357). SLT acknowledges funding for the STM instrument from the METACyt Initiative, Indiana University. AHF acknowledges the NSF (CHE1412401) for support of compound synthesis and X-ray crystallography.

\section{Notes and references}

1 S. De Feyter and F. C. De Schryver, Chem. Soc. Rev., 2003, 32, 139-150.

2 M. M. S. Abdel-Mottaleb, E. Gomar-Nadal, M. Surin, H. Uji-i, W. Mamdouh, J. Veciana, V. Lemaur, C. Rovira, J. Cornil, R. Lazzaroni, D. B. Amabilino, S. De Feyter and F. C. De Schryver, J. Mater. Chem., 2005, 15, 4601-4615.

3 J. Adisoejoso, K. Tahara, S. Okuhata, S. Lei, Y. Tobe and S. De Feyter, Angew. Chem., Int. Ed., 2009, 48, 7353-7357.

4 O. Ivasenko, J. M. MacLeod, K. Y. Chernichenko, E. S. Balenkova, R. V. Shpanchenko, V. G. Nenajdenko, F. Rosei and D. F. Perepichka, Chem. Commun., 2009, 1192-1194.

5 M. O. Blunt, J. C. Russell, M. D. C. Gimenez-Lopez, N. Taleb, X. Lin, M. Schröder, N. R. Champness and P. H. Beton, Nat. Chem., 2011, 3, 74-78.

6 A. Ciesielski, S. Lena, S. Masiero, G. P. Spada and P. Samorì, Angew. Chem., Int. Ed., 2010, 49, 1963-1966.

7 M. M. S. Abdel-Mottaleb, N. Schuurmans, S. De Feyter, J. Van Esch, B. L. Feringa and F. C. De Schryver, Chem. Commun., 2002, 1894-1895.

8 P. Zell, F. Mögele, U. Ziener and B. Rieger, Chem. - Eur. J., 2006, 12, 3847-3857.

9 H. Maeda, T. Shirai and S. Uemura, Chem. Commun., 2013, 49, 5310-5312.

10 S. Lee, C.-H. Chen and A. H. Flood, Nat. Chem., 2013, 5, 704-710.

11 M. Parschau, R. Fasel, K.-H. Ernst, O. Gröning, L. Brandenberger, R. Schillinger, T. Greber, A. P. Seitsonen, Y.-T. Wu and J. S. Siegel, Angew. Chem., Int. Ed., 2007, 46, 8258-8261.

12 M. Pivetta, M.-C. Blüm, F. Patthey and W.-D. Schneider, Angew. Chem., Int. Ed., 2008, 47, 1076-1079.

13 S.-S. Jester, E. Sigmund and S. Höger, J. Am. Chem. Soc., 2011, 133, 11062-11065.

14 K. Tahara, T. Balandina, S. Furukawa, S. De Feyter and Y. Tobe, CrystEngComm, 2011, 13, 5551-5558.

15 N. A. Wasio, R. C. Quardokus, R. P. Forrest, C. S. Lent, S. A. Corcelli, J. A. Christie, K. W. Henderson and S. A. Kandel, Nature, 2014, 507, 86-89.

16 A. Dürer, Treatise on Mensuration with the Compass and Ruler in Lines, Planes, and Whole Bodies, Dürer, 1525.

17 B. Qin, X. Chen, X. Fang, Y. Shu, Y. K. Yip, Y. Yan, S. Pan, W. Q. Ong, C. Ren, H. Su and H. Zeng, Org. Lett., 2008, 10, 5127-5130.

18 M. G. Rossmann, Acta Crystallogr., Sect. A: Found. Crystallogr., 1990, 46, 73-82.

19 L. Zoppi, T. Bauert, J. S. Siegel, K. K. Baldridge and K. H. Ernst, Phys. Chem. Chem. Phys., 2012, 14, 13365-13369.

20 Q. S. Stöckl, D. Bandera, C. S. Kaplan, K.-H. Ernst and J. S. Siegel, J. Am. Chem. Soc., 2013, 136, 606-609.

21 W. Xiao, D. Passerone, P. Ruffieux, K. Aït-Mansour, O. Gröning, E. Tosatti, J. S. Siegel and R. Fasel, J. Am. Chem. Soc., 2008, 130, $4767-4771$.

22 D. Bandera, K. K. Baldridge, A. Linden, R. Dorta and J. S. Siegel, Angew. Chem., Int. Ed., 2011, 50, 865-867.

23 T. Kudernac, N. Shabelina, W. Mamdouh, S. Hoger and S. De Feyter, Beilstein J. Nanotechnol., 2011, 2, 674-680.

24 B. E. Hirsch, K. P. McDonald, B. Qiao, S. L. Tait and A. H. Flood, 2014, submitted.

25 The low polarity of TCB would suggest the counter cation will pair with the negatively charged complexes. However, when the anions are hidden inside the dimer complexes, we have shown the affinites for the counter cation often drop below detection in solution studies; see: Y. Hua, R. O. Ramabhadran, E. O. Uduehi, J. A. Karty, K. Raghavachari and A. H. Flood, Chem. - Eur. J., 2011, 17, 2312-2321.

26 S. J. H. Griessl, M. Lackinger, F. Jamitzky, T. Markert, M. Hietschold and W. M. Heckl, J. Phys. Chem. B, 2004, 108, 11556-11560.

27 D. F. C. Morris, Acta Crystallogr., 1961, 14, 547-548.

28 R. O. Ramabhadran, Y. Liu, Y. Hua, M. Ciardi, A. H. Flood and K. Raghavachari, J. Am. Chem. Soc., 2014, 136, 5078-5089.

29 R. O. Ramabhadran, Y. Hua, A. H. Flood and K. Raghavachari, J. Phys. Chem. A, 2014, DOI: 10.1021/jp412816w. 